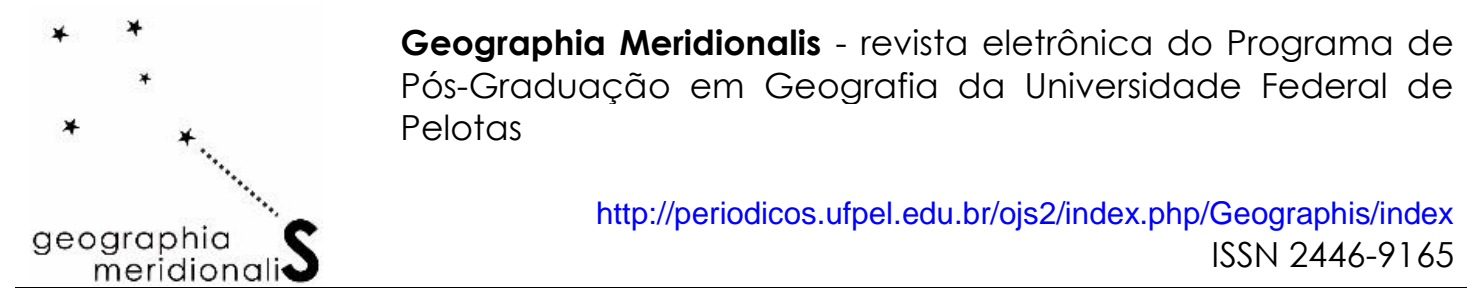

\title{
NOTA SOBRE O I SEMINARIO DO PROGRAMA DE PÓS-GRADUAÇÃO EM GEOGRAFIA DA UFPEL
}

Maurício Meurer

Universidade Federal de Pelotas, Departamento de Geografia mauriciomeurer@yahoo.com.br

Nos dias 26, 27 e 28 de Novembro de 2014 o PPGeo/UFPel - Programa de Pós-Graduação em Geografia da Universidade Federal de Pelotas realizou a primeira edição do SEMPGEO - Seminário do Programa de Pós-Graduação em Geografia da UFPel. Este seminário surgiu a partir de uma recomendação dada pela CAPES para que o programa desenvolvesse iniciativas que aumentassem a sua visibilidade e inserção no cenário acadêmico de Pós-Graduação brasileiro.

Organizado pelos discentes e docentes do programa, e contando com o apoio do Departamento de Geografia, o I SEMPGEO buscou proporcionar uma integração entre discentes e docentes do PPGeo/UFPel, e também destes com as demais instituições de ensino e pesquisa participantes. Esta integração se deu a partir da realização de palestras, da socialização dos trabalhos científicos (em desenvolvimento ou concluídos) apresentados, e a partir da realização de espaços de diálogo nos eixos temáticos de interesse do programa.

Nesta primeira edição, o SEMPGEO teve como tema "Pesquisa em Geografia: Desafios e Perspectivas na Contemporaneidade". A definição deste tema partiu dos próprios discentes do programa, que mostraram a preocupação em discutir sobre como o processo de pesquisa deve ser planejado e conduzido considerando todas as transformações metodológicas, tecnológicas, políticas e conjunturais que estamos vivenciando nesta contemporaneidade. Quais as vantagens de se trabalhar neste novo contexto? Que entraves e desafios surgem ao se fazer pesquisa neste momento histórico? Como novas e velhas metodologias têm se combinado para dar conta de explicar as questões que investigamos? Que novos assuntos despontam na pesquisa em Geografia na contemporaneidade? Estas, e muitas outras questões que surgiram dos debates entre 
discentes e docentes orientaram para a definição do tema do seminário, e posteriormente orientaram muitas das discussões feitas ao longo do evento.

A programação do seminário e as apresentações de trabalho foram organizadas sobre três eixos, que alinham-se com as pesquisas realizadas no programa: 1) Ensino de Geografia; 2) Produção do Espaço Urbano e Rural; e 3) Análise Ambiental. Em cada uma das três noites do evento, uma palestra com um pesquisador de reconhecida competência em sua área de atuação contemplou um dos eixos temáticos do evento.

Na noite do dia 26 de novembro, a palestra de abertura foi proferida pelo Prof. LivreDocente João Osvaldo Rodrigues Nunes (UNESP - Presidente Prudente). Nesta palestra, que teve como tema "Práxis Geográfica e suas Conjunções", o palestrante apresentou os resultados de sua recém defendida tese de Livre-Docência, onde o mesmo abordou toda sua trajetória como professor/pesquisador na área de Geomorfologia, a construção do seu arcabouço teórico-metodológico ao longo desta trajetória, a sua identificação epistemológica com determinadas linhas e autores, e como esta trajetória e este arcabouço teórico se fundiram em sua "práxis" ao longo de seus anos de trabalho.

Na segunda noite do evento, no dia 27 de Novembro, a palestra foi proferida pela Profa. Dra. Lana de Souza Cavalcanti (Universidade Federal de Goiás), e teve como tema "Conteúdos geográficos e a Formação de Conceitos no Cotidiano Escolar". Ao longo de sua fala, a Professora Lana Cavalcanti debateu a questão do ensino dos conceitos no cotidiano escolar, enfatizando a importância da utilização destes conceitos (sejam eles naturais ou sociais) para que o aluno os compreenda de uma forma contextualizada. Esta prática permitiria ao aluno uma nova leitura do espaço ao seu redor, e permitiria a este também entender qual o seu papel neste espaço, trazendo assim maior sentido a noção de Espaço Geográfico.

Na terceira noite do evento, no dia 28 de Novembro, foi organizada uma mesa com duas palestrantes: a Profa. Dra. Vera Lúcia Salazar Pessôa (Universidade Federal de Goiás Campus Catalão) e a Profa. Dra. Rosalina Burgos (Universidade Federal de São Carlos Campus Sorocaba). A Professora Vera Pessôa abordou a temática "Pesquisa Qualitativa: reflexões em Geografia". Ao longo de sua fala, a palestrante reforçou a importância da adequação do trabalho de pesquisa às normas técnicas vigentes, bem como a importância de se ter uma clareza quanto aos aspectos metodológicos da pesquisa. Posteriormente, a 
palestrante apresentou brevemente uma síntese das reflexões que vem fazendo sobre o uso de metodologias qualitativas nas pesquisas geográficas, demonstrando a necessidade que as ciências humanas e sociais têm de trabalhar com métodos que consigam ir além da quantificação, e que não necessariamente estejam vinculados à ideia cartesiana de método. Em um segundo momento da mesa a Professora Rosalina Burgos apresentou reflexões, métodos e resultados de algumas das pesquisas qualitativas que vem coordenando na cidade de Sorocaba. Em sua fala, a palestrante apresentou os números oficiais dos grandes projetos urbanísticos e viários que estão sendo conduzidos pela Prefeitura de Sorocaba, mostrando como a Prefeitura encara tais projetos (através de um viés utilitarista e de um discurso de modernidade), e contrapôs este discurso com imagens, resultados de entrevistas com os moradores diretamente atingidos por tais projetos. Ao final, a palestrante demonstrou claramente que muitos dos problemas identificados não são evidentes quando a análise é feita somente a partir de métodos quantitativos, e que os excelentes números divulgados pela Prefeitura de Sorocaba não expressam a real situação da tensa questão urbana deste município.

Em duas tardes do evento foram realizadas as sessões de apresentações de trabalhos. Os trabalhos de estudantes de Pós-Graduação foram apresentados em sessões orais de acordo com os três eixos propostos pela organização. O seminário abriu ainda espaço para estudantes de Graduação apresentarem seus trabalhos sob a forma de pôsteres, promovendo assim uma integração entre Graduação e Pós-Graduação. Além disto, a participação dos estudantes de Graduação permitiu que estes estudantes tivessem os seus trabalhos apreciados e avaliados pela comissão científica do evento, que fez as suas contribuições e sugestões para o avanço destas pesquisas.

Durante o evento aconteceu ainda a sessão de lançamento do livro "Agriculturas Familiares: estratégias de reprodução social e territorial". O livro foi organizado pela Profa. Dra. Giancarla Salamoni e pelo Prof. Dr. Adão José Vital da Costa, ambos membros do LEAA - Laboratório de Estudos Agrários e Ambientais, um dos grupos de pesquisa componentes do PPGeo/UFPel. Este livro é o resultado da participação dos pesquisadores deste laboratório na REA - Rede de Estudos Agrários, que reúne ainda o NEA - Núcleo de Estudos Agrários (Universidade Estadual Paulista - Campus de Rio Claro) e do NEPGeR - Núcleo de Estudo e Pesquisa e Geografia Rural (Universidade Estadual de Montes Claros). A publicação concentra os resultados e reflexões das 
pesquisas realizadas pelos pesquisadores desta rede ao longo do ano de 2011, com importantes contribuições em temáticas como a Agricultura Familiar, a Agroecologia, e a Produção e Reprodução do Espaço Rural nos três estados pesquisados (RS, SP e MG), além de propostas metodológicas para a realização de pesquisas nestas temáticas.

Os resultados da organização deste I SEMPGEO foram considerados muito positivos tanto pela organização do evento quanto pela coordenação do PPGeo/UFPel. O seminário permitiu a vinda de pesquisadores extremamente qualificados a cidade de Pelotas, e trouxe uma maior visibilidade ao programa dentro e fora da universidade. Durante o evento, participantes de outras universidades se fizeram presentes (FURG, UFRGS, UCPel, IFSUL, UNESP - Rio Claro), e puderam conhecer um pouco mais sobre a proposta do PPGeo/UFPel, sobre suas pesquisas e suas contribuições.

Após o I SEMPGEO, outras mudanças positivas foram observadas, muitas delas com relação direta com a organização deste evento. O PPGeo/UFPel oteve um expressivo aumento em sua produção discente em relação ao ano anterior; os docentes do programa têm sido frequentemente convidados para participarem de atividades em outros programas de Pós-Graduação (tais como bancas, palestras, cursos, etc.); as visitas ao website do programa aumentaram em número e abrangência espacial, mostrando que a visibilidade do programa tem aumentado progressivamente.

É desejo da coordenação e do corpo docente do PPGeo/UFPel que este seminário venha a se tornar uma atividade regular, de maneira a possibilitar novas interações, novas discussões, a abertura de novas frentes de pesquisa e a contínua qualificação dos docentes e dos discentes de Pós-Graduação e Graduação. 